\title{
Screendance in the Wake of Screened Dance: Moving Forward Through Interactive Video
}

Callum Anderson, Independent Scholar

\section{Abstract}

This paper argues that screendance has always had a potential for interactivity, looks specifically at interactive video, and tracks its history through video art and video games. Taking into account the higher volume of dance that is migrating to the screen as a result of the Coronavirus/Covid-19 pandemic, it also suggests a new term, screened dance, to differentiate those dances and dance events which otherwise would have been live and co-present. Bringing together a transmedia screendance work that unfolded on social media, and interactive narrative works currently available to stream on Netflix, I argue that the innovations and adaptation in the delivery of dance content due to lockdowns imposed by Covid-19, have provided an opportunity for the possibility of interactive screendance.

Keywords: interactive video, video games, screened dance, Covid-19, social media

Screendance has always had a potential for interactivity, but this paper argues that this potential has rarely been realized and accessed on a mass scale. Departing from this idea I will look to argue that the higher volume of dance that is migrating to the screen as a result of the Coronavirus/Covid-19 pandemic, and subsequent enforced lockdown, offers an opportunity for screendance to distinguish itself from other dance practices and enhance the practice via the inclusion of interactivity. For the purposes of this paper, lockdown will refer to the time between late March and approximately early June 2020 in the United Kingdom, although it is still ongoing in some form as this paper is being written.

Looking specifically at interactive video and tracking its history through video art and video games to its place in mainstream streaming culture, I hope to bring together the development of interactive performance and the ways in which these speak to interactive video specifically. I have included video games in this discussion as they developed parallel to interactive video and hope that this will aid in bringing together performance and entertainment theories and practices, situating interactive video and 
the possibility of interactive screendance. By examining these other practices I hope to be able to provide not only a historical context, but as is often necessary when discussing emerging art forms, to also borrow their language to aid the discussion.

I would also like to suggest a new term to differentiate those dances and dance events which underwent mass-migration to screen space in the Covid era which otherwise would have been live and co-present; in this paper I refer to these performances, classes, and festivals as screened dance. I hope that this naming illustrates screened dance's relation and similarities to screendance practice, but still positions it as departure from existing understandings of the term. Additionally, labeling these works and events highlights their importance to the current screendance landscape.

In the final section of this paper, I will examine works from dance and film that take place across the web, social media and streaming platforms. Primarily, I will look at the 2015 transmedia work by Lea Anderson and Marisa Zanotti, The Pan's People Papers, ${ }^{1}$ and consider two mainstream narrative interactive works, Black Mirror: Bandersnatch, ${ }^{2,3}$ and Unbreakable Kimmy Schmidt: Kimmy vs. the Reverend ${ }^{4}$ to examine how techniques used in them might be translated into a screendance space. By incorporating these techniques, I hope that it might be possible to differentiate screendance from other practices, and contend with the ever changing digital landscape by further interrogating the ways in which screendance works are presented.

\section{Screendance or Screened Dance?}

Defining and naming screendance is something that has been debated since the name's inception, but for the purposes of this paper I will be aligning my definition with Douglas Rosenberg's, as an "experiment with choreographic form as well as the formal structure of filmmaking itself, altering camera placement, shot composition, and visual space to find the most efficient and esthetic methods of framing movement." ${ }^{5}$ Screendance then, is the practice of creating dance explicitly for the screen, whereas I suggest 'screened dance' is something else. I would define screened dance as work that was not primarily intended for the screen, but which has migrated to screen space as a necessity.

This is not the first time that scholars have tried to explain the differences between what I am referring to as screendance and screened dance. Vera Maletic made the argument in the Dance Research Journal of Winter 1987-88, "that a distinction must finally be made between video dance and video taped dance." Maletic goes on to describe video dance as "a blending of structural and perceptual elements intrinsic to dance and the media," whereas video taped dance is shot as a "record tape in place of the dance score." ${ }^{17}$ As we have moved away from analogue video recording to a digital screen, I hope that the move from 'video dance' to 'screendance' can also be made from 'video taped dance' to 'screened dance.' In essence, I would say that screendance is made for the screen, and if you take the screen away the work would no longer remain. Screened dance is work 
that has come to the fore in its migration to screen space because of the closure of theaters and dance settings and although it is currently prolific-as Maletic's analysis shows it already existed in some form prior to the pandemic — this work can and likely will easily return to a live space.

To further parse the distinction between screendance and screened dance, I would like to highlight the first show on Sadler's Wells's 'digital stage': BalletBoyz - Deluxe (2020) launched on Friday 27 March 2020, in celebration of World Theatre Day. The digital stage gave a platform for Sadler's Wells to stream recordings of a variety of work, available for a seven-day period. I am singling this show out in particular as it involves works of screendance and screened dance. The first work in the trilogy is a screendance work by Sarah Golding, The Intro (2020). The six 'Boyz' in white boiler suits, take over a black box space, vying for attention from each other and the audience. The proximity of the dancers to the camera, the cutting of camera angles to the movement and the music, the dancers interacting with the camera and ending by looking directly into the lens to meet the audience members' gaze, are all techniques available when making a screendance work. Billed as a 'short dance film,' this work was never intended to be performed live, and was due to be shown as a film on the live tour. It is clear that producers Michael Nunn and William Trevitt have separated it from the two works that follow.

Ripple (chor. Xie Xin) and Bradley 4.18 (chor. Maxine Doyle) ${ }^{8}$ are filmed versions of existing stage works and by my suggestion, are examples of screened dance. They both rely on two cameras recording simultaneously, one from the back of the auditorium and one from the front side stage. The cameras do not move, and are often out of focus or over-exposed, suggesting that these works were not primarily intended to be shown as films, but are rather what Maletic has described as a "record tape in place of the dance score" made available due to the imposed lockdown. By placing these works next to each other it is easier to see the distinction that I am making between choreography made explicitly for the screen, and work that was intended for the live stage that has migrated to screen space through necessity. As of the time of writing, The Intro is still available to watch on YouTube, whereas the other works that were screened as part of the digital stage are no longer available, further suggesting that these screened dance works were not intended to replace the live performance.

Screened dance, I suggest, has an inherent potential for interactivity and has already begun training audiences to interact with media, priming them for interactivity. Here I am referencing the dance classes available online, the 'digital stages' that some theaters have established to stream past productions, or even Zoom meetings dance communities have set up in order to meet digitally. These screened dance activities have to be searched out and searched for by audience members, but more importantly, perhaps through analogy of their co-present versions, they promote an active and interactive style of viewing and a base for more 'devised' interactivity, beginning to unpair interactivity and narrative. You are able to take a class (active) at a time that suits you 
(inter-active). You can join a live streaming of a work from a theatre (active) or you can watch it later; pausing, rewinding or fast forwarding as you wish (inter-active). ${ }^{9}$ And in the case of Zoom meetings or live classes on other platforms, you can interact with other people on the call through your camera, microphone, chat functions, or reactions. These aspects of interactivity can be heightened when performances are only streamed for a short period of time, increasing the 'want' to search them out and helping to keep some of the ephemerality of live performance. As interactive works are predicated on choice, you might not watch the same work if you revisited it and chose a different path, just as a live work will not be exactly the same in every performance; as described by Matthew Reason, "performance passes in time; [...] it has no physical durability or permanence; [...] its existence is temporary."10 A film, on the other hand, will repeat without change to the footage or edit, so interactivity may bridge the gap between permanence and ephemerality.

I have already highlighted how screened dance lends itself to some notions of interactivity in terms of 'active' and 'inter-active,' however I would suggest that screendance does not share this relationship quite as intrinsically. You may have to search for a screendance work, perhaps find a screendance festival in the same way as you might search out any form of performance, but that is where I contend the interactivity usually stops. Screendance, especially in the gallery and festival context, like many forms of Western concert dance and theatre, often allows you to just sit and watch, and can be 'escapist,' inviting audience members to enjoy and be entertained." In the next section, I discuss how streaming sites have developed interactive content and how screendance has begun to investigate interactivity, but I find that the majority of current screendance practice aligns itself with more traditional forms of film in terms of lack of simultaneous audience interaction.

Screened dance as such, I argue, has coalesced in light of Covid-19. Necessity and ubiquity have amplified the potential of screened dance, broadly normalized what has been community-level conventions, such as screendance festivals, and made people accustomed to a certain degree of interactivity, perhaps altering the trajectory of screendance practice. I argue that this amplifying and normalizing of screened dance has in turn increased the availability of screendance, making it more accessible to a wider audience base. It is my belief then, that with new and newly trained audiences, screendance practice is ripe for developing interactivity, as some streaming sites have begun to do with television and film. In other words, the trajectory of screened dance during Covid has opened up new creative opportunities for screendance. In the following sections, I discuss the possibilities of incorporating interactive video techniques to move screendance practices forward. 


\section{Interactive video and video games in a world of streaming}

Interactive video is often described in relation to a choose-your-own-adventure book, ${ }^{12}$ where the reader is able to make narrative choices by turning to different pages at key points in the plot. Similarly, interactive video allows the viewer to make choices at key points in the work which sends them down different 'branches' which in turn affects the story arc. Interactive video has developed since the 1908s along with technology, taking the form of gallery-based work, video games, and early YouTube videos.

It is widely believed that the first work of interactive video was Lynn Hershman's Lorna (1984). ${ }^{13}$ Developed out of a frustration with video as a "one sided discourse; like a trick mirror that absorbs instead of reflects," ${ }^{14}$ the work encourages the viewer to make "surrogate decisions"15 for the titular character through a branching design of the video disk, which leads through to multiple endings as well as multiple treatments of the video footage (sped up, slowed down, reversed etc.). Writing six years later, Hershman acutely asserts the problems with Lorna, particular to the drawbacks of the available technology in the mid-1980s. She suggests "[Lorna] is generally inaccessible. It was pressed in a limited edition of twenty-five, of which only fourteen now exist. It is only occasionally installed in galleries or museums. Creating a truly interactive work demands that it exists on a mass scale, available and accessible to many people. ${ }^{\prime 16}$ In the near 40 years since Lorna was first pressed onto disk, technology has taken strides forwards in how interactive video is produced and 'performed,' particularly with the development of digital technologies. These developments have turned the inaccessible, small scale production into a mass market for anyone with a smart phone and an internet connection.

The narrative-led video game is a very clear form of interactive video. So named because of the live action video clips that link the stages of game play, narrative-led video games have become a staple of entertainment ${ }^{17}$ and have been further developed for game streaming services and platforms. They have developed beyond 'story mode' to a 'free play' where the player is able to make their own decisions in the world that their animated self (avatar) inhabits. This development from live action clips used to link sections to a fully realized CGI world has enabled many more 'branches' to emerge within a story, giving the player "considerable control over the text and its narrative."18 Taking into account the development of video games and how this has informed the establishment of interactive video through streaming services and multimedia traversable software, ${ }^{19}$ it is possible to see how by building on clear user navigation, it might play a part in interactive art and the possibilities of interactive screendance.

A strong narrative directed by video clips placed within game play, and a clear technique for the player to interact and affect the game play, it is logical to see the initial links between video games and interactive video. The first laser disk video game Astron Belt, ${ }^{20}$ was released in 1982, around a similar time as Lorna was being developed. So popular was this style of video game, that it spawned further games through the 1980s 
and 90s, with live action scenes linking together stages as you progressed through the game's narrative. Developing through VHS tapes, CD-ROMs as they were embedded into home computers, and on to DVDs and blu-rays (some as companions to board games), ${ }^{21}$ the way that these narrative style games were marketed, sold and massproduced specifically for the home differentiates them from the interactive video art which relied on installation in galleries or museums.

YouTube has become a leader in video streaming since its inception in 2005. Championing 'indie creators' (content creators that are independent from big production companies) as well as being utilized as a vlogging platform, it had a brief stint as a platform for interactive video. In 2008 it developed 'annotations,' clickable images or text that would encourage audiences to make a choice at a particular point in the video. ${ }^{22}$ Using this feature, American filmmaking trio Chad Villella, Matt BettinelliOlpin and Rob Polonsky, known collectively as Chad, Matt \& Rob, created a series of five Interactive Adventures between 2008 and $2011 .{ }^{23}$ Directly linking back to the idea of the choose-your-own-adventure book, audience members navigated through the story making choices that would then lead to a different video. In 2019 YouTube announced that they were bringing an end to annotations, and removing all annotations in previously published videos. ${ }^{24}$ YouTube developed Cards and End Screens that had mobile functionality to meet with increased use of YouTube on mobile devices, as annotations were not accessible on mobile. Although they act in a similar way, they do not have the same in-video experience that annotations gave. Other platforms have since been developed; the most similar to YouTube in terms of free access to publishing is Eko. ${ }^{25}$ Developed as a software for the construction of 'multimedia traversable video trees,' Eko streams in a similar way to YouTube, creating a software that is as accessible to indie creators and to broad audiences.

Mirroring Hershman's assertion that true interactivity comes with wide reach, video game popularity and interactivity accelerated with their availability in the home and on personal and mobile gaming devices, and video-sharing sites are attempting to follow the same trajectory. These other forms of interactive entertainment developed in parallel to screendance and its move to a digital format. I suggest that similarly there will be a wider audience for interactive video, and interactive screendance in particular, as works become more mobile friendly and more easily available, allowing audience members to create their own narratives and other more individual experiences of the work.

\section{Interactivity, Performance and Social Media}

In this final section I will discuss The Pan's People Papers (2015), a transmedia ${ }^{26}$ work by Lea Anderson and Marisa Zanotti, alongside Black Mirror: Bandersnatch (2018) and Unbreakable Kimmy Schmidt: Kimmy vs. the Reverend (2020), two feature films, as mainstream examples of interactive video. While these are narrative works without 
dance in them, they are worth analyzing in this context because audiences are likely to have engaged with them. Looking at the works for their formal and technical aspects allows for them to serve as models for how interactivity may be applied to screendance practice.

The Pan's People Papers (2015) is a multi-platform transmedia work by filmmaker Marisa Zanotti and choreographer Lea Anderson. It explores the work of Flick Colby and the 1970s dance group, Pan's People. Pan's People was a British all-female dance troupe who appeared on the BBC TV chart music show Top of the Pops from the late 1960s to the mid-1970s. The Pan's People Papers imagines the Greek Gods, Pan and Echo, as choreographer and dancer alongside the fictional multi-national Pan Global. Coupled with videos on YouTube, it is now an online archive. ${ }^{27}$ Taking place in real time over a three-day period, audiences were invited to search out the posts from across Pan's and Echo's feeds on Twitter, and discover how these characters were interacting, while piecing together prophecies and short screendance choreographies of "Pan's Revels at the Woods" as part of the first paper, "A Legion of Echoes." ${ }^{28}$

From The Pan's People Papers, it is possible to see how the notion of choose-your-ownadventure has taken on a different form. Unlike interactive video or video games, the narrative is not set out for you, but rather there for you to discover. Although the posts and videos unfolded in real time, it would be unlikely that audience members would experience it in the same way if it was presented on a single platform or as a single screen work. It does, however, show what is possible in terms of breaking up a narrative form, and what this can afford to the practice of screendance. Although the work developed in real time, it was not 'live' in the literal sense as the posts and films had been planned and prerecorded, but it had a feeling of risk ${ }^{29}$ and individual experience as each audience member would have discovered the work at a different rate. Had audience members missed a post, or seen a video not in the intended order, this may have affected the narrative that the audience member was constructing. Liveness is something that has often been argued is missing from film and thus impacts on its risk, or spontaneity. Philip Auslander argues that "liveness [is] the one aspect of theatrical presentation that film could not replicate, ${ }^{\prime \prime 30}$ whereas interactive video re-introduces the possibility of risk, primarily by making 'mistakes,' something which is very much possible with live performance. I will return to the idea of making mistakes in interactive video when discussing the mainstream narrative interactive works below.

I have looked at this work, as it goes some way to distinguish screendance from other forms of dance and film, because although you interact with the work through textbased social platform posts, short films were also released over the three-day duration of the work and the final 'pay off' was a more traditional style of screendance with the work $A$ Legion of Echos. In this way, it is possible to see how we might marry together known screendance practice of "experiment[ing] with choreographic form as well as the formal structure of filmmaking itself," ${ }^{31}$ while using the intersection of digital technology to move the practice of screendance forward. 
Many scholars have discussed the "myth of choice" 32 in interactive video; with interactivity we are given a choice, however this choice is constrained by the options provided by the choreographer and/or director. Therefore, the choice carries an element of myth as the choices made have ultimately been predetermined. Despite the predetermination, risk may still be felt by users in an interactive video. An audience member's choices can pivot the arc of the narrative or lead to an 'out,' one of many multiple endings which may lengthen or shorten the runtime. In interactive videos currently available, the way that audience member's choices might pivot the narrative or lead to an out has been treated in a number of ways. An out is the point at which audience members can exit the interactive video, similar to the way you might end a video game by completing the story. Narrative pivot points, often presented as an $A / B$ or $A / B / C$ choice via on-screen text, are more reminiscent of reaching a save point in a video game. Save points are moments within long-form narrative video games at which your progress can be saved and then returned to, such as when your avatar is defeated, or after a break in gameplay; at a pivot point, a choice is made which leads to a different branch of the narrative.

Black Mirror: Bandersnatch and Unbreakable Kimmy Schmidt: Kimmy vs. the Reverend are both interactive episodes of previously successful series available on the streaming platform, Netflix. Black Mirror is a dystopian science fiction anthology series, and Bandersnatch follows Stefan Butler as he creates a video game based on a choose-yourown-adventure book of the same name. The narrative of the work matches and borrows aspects of the branching pathways and choices available to players of the fictional game, as well as audience members as they interact with the episode.

In Bandersnatch, the pivot points lead to five possible endings, ${ }^{33}$ with some pivot points also working as outs. Any choice made which could be described as a 'mistake,' such as a choice which results in the death of a character, will allow you to either end the story at that point or go back to your last choice in order to amend your selection. These earlier choices, which are more like save points, allow audiences the chance to make 'mistakes' as a way of learning how the interactive video operates. ${ }^{34}$ I previously suggested that these different outs could lengthen or shorten the run time, and this is true of Bandersnatch. At its shortest, it is reported to be around 40 minutes, with an average run time of 90 minutes. ${ }^{35}$

Building on the success of Bandersnatch, Netflix released Kimmy vs. the Reverend in 2020 during the Covid-19 lockdown. Billed as the interactive finale to the story of Kimmy Schmidt who was held in a cult-esque bunker by the Reverend who tells her that life on earth has been destroyed, this is Netflix's first attempt at a comedic interactive video. Kimmy vs. the Reverend treats pivot points and outs in a much simpler way. Each time you select an 'incorrect' answer, you are shown the effect of your choice, before being taken back to the moment the choice was made so that you can choose the 'correct' option. Television critic Jen Chaney refers to the work as "plot-driven in theory but jokedriven in reality, ${ }^{136}$ and this can be seen in the treatment of the pivot points. In one 
choice, audiences are asked who Kimmy should ring, and although there is a 'correct' choice which will advance the narrative, the other choices allow audience members to see different character's reactions for comedic effect, before being taken back to the point at which the choice is made. Kimmy vs. the Reverend in effect does not use multiple outs, but rather utilizes techniques of interactive video to provide multiple punch-lines to jokes.

Chaney makes an interesting assertion that interactive videos are usually plot-driven. ${ }^{37}$ The plot-driven idea is something that has been used widely throughout video games, as well as the interactive video, or video art that is available. Kimmy vs. the Reverend shares some similarities with video games in its construction. As well as the choices acting as 'save points,' and an ability to explore paths without detriment, an even clearer nod to its links to video games is the ending. If you successfully get to the end of the story then you are rewarded by seeing the first choice you made come to fruition, and the words "you won!" fill the screen recalling interactive video's links to video game practice.

Looking at these different works across screendance and interactive video, I hope that by identifying the use of interactivity across these varying pieces it is possible to link interactivity to the practice of screendance

\section{Conclusion: Interactivity in and after Screened Dance}

The examples of interactive video available on Netflix that I have mentioned push the boundaries of how audience members might interact with entertainment. Mainstream narrative interactive video also mimics the mechanisms and experience of video games, as audience members can see the narrative unfolding and can more clearly understand how their choices are affecting what is being played out, as with Kimmy vs. The Reverend when the first choice directly affects the final scene. The developments in the narrative works I have discussed lay out the possibilities for interactive screendance, too, in order to push the boundaries of how audience members interact with choreography.

In order to translate the mechanisms of plot-driven work into a movement- or themedriven style for screendance audiences, some specific techniques can be utilized as-is, and others will require adjustments. For example, I have looked at pivot points and outs as techniques for controlling the narrative arc of a work, but also, as in Kimmy vs the Reverend, as a kind of formal exploration through the inclusion of multiple punch-lines that in fact do not impact the narrative. These could also be employed in terms of a choreographic theme or movement vocabulary, similarly to how audience members had to search out the posts and videos of The Pan's People Papers in order to piece together the narrative being built. I have noted how interactivity could bring about a sense of risk and agency, with choices leading to an active rather than escapist audience experience. 
In contrast, I would argue that changes are necessary in the way that audience members are presented with a choice. In current interactive video, you are presented with an $A / B$ or $A / B / C$ choice as a word or short sentence which appears on the screen, which you can then highlight and select. For movement however, this text-based choice system would not easily translate, movement descriptions likely being too long. To combat this, one suggestion may be the inclusion of gifs at these choice points. I would like to suggest the use of gifs as an extension of the idea of aesthetic glitch offered by Peter Krapp. Although Krapp does not speak directly about gifs, he does suggest that "aesthetic expressions in digital culture seek to be recognized as entirely new and inheriting the legitimacy of any serious art that preceded it"138 and goes on to assert that "since cut and montage and liner prediction code, cinema and new media have revolutionized our sense of time and space." ${ }^{39}$ A gif could be seen as a visual representation of a digital glitch, making interactive screendance work both part of a generic lineage and uniquely of this moment, while also actively playing with an audience member's sense of time and space. By sectioning off the screen, and showing audience members short repeating sections of movement that they will see after making their choice, this may go some way to translating current interactive video practice into a 21 st century screendance space. This change in how audience members are presented with a choice has also been explored by Alleyne Dance in their recent piece, (Re)United. ${ }^{40}$ An interactive short dance film, the work presents a choice by splitting the frame in half and placing short pieces of text over the two dancers moving in isolation. These choices allow audience members to follow either of the two dancers before they are reunited in physical space, and onscreen. This combination of text and movement allows, in part, for both a plot-driven and movement-driven choice to occur.

Innovations and adaptations in the delivery of dance content due to lockdown imposed by Covid-19 have provided an opportunity to differentiate between screendance and screened dance practice in a way that introduces nuance into the discourse and that has important implications for the possibility of interactive screendance. First, as audiences are currently more used to streaming videos and dance into their homes, it could be possible to parallel the way video games-a highly interactive screen genregained popularity as they were placed directly into peoples' homes, whereas this development has largely left interactive video to gallery installations. Further, given the way screened dance has required active participation and interaction through choice, scheduling, control of speed and replay, I argue that dancers and dance audiences are primed and practiced in a kind of interactivity. I suggested that now might be the time to implement interactive video practice into screendance using this new literacy from screened dance, as some are already interacting on various platforms as delineated at the beginning of the article. Covid-19 has affected dance in myriad ways, many of them negative. However as more people are getting used to screened dance, in combination with increased time viewing screendance, as well as potentially interactive modes like video game, choose-your-own-adventure narrative episodes, and various forms of social video, the impact of Covid-19 on viewing and entertainment habits may have a 
positive effect on screendance practice, interactive video being just one way of bringing screendance further out of the gallery.

\section{Biography}

Callum Anderson is a Brighton-based contemporary dance artist and screendance director. As an independent artist-scholar, his practice is heavily influenced by video technology, and the development of digital and mediated dance performance. His work is predicated on making screendance accessible to a wider non-dance community, and giving dance communities the opportunity to experiment with video technology. Working across live and digital performance, he has made work for large scale screens, portable devices and installations. Alongside an interest in technological advances in video presentation, his research focuses on the representation of men in dance and on-screen, principally the representation of queer masculinities. In January 2021 he was awarded a commission from the Sussex Dance Network which aimed to address the underrepresentation of those identifying as LGBTQ+ in the dance sector, as demonstrated in Arts Council England's most recent Equality and Diversity report. He holds a BA (Hons) in Dance and MA in Performance: Dance, from the University of Chichester, and received the Valerie Briginshaw Prize 2018 for dance writing and academic excellence for his MA thesis From big screen to screen dance; queering the heterocentric (2017). Find Callum online @CallumAnderson.

\section{Email: cal_anderson@me.com}

\section{Notes}

${ }^{1}$ Anderson and Zanotti, "Glossary: Pan's People Papers."

2 Slade and Kearns, "Black Mirror: Bandersnatch."

${ }^{3}$ Written by Charlie Brooker (Dir. David Slade. Ed. Tony Kearns).

${ }^{4}$ Fey, et. al. "Kimmy vs. the Reverend."

${ }^{5}$ Rosenberg, Screendance, 1.

${ }^{6}$ Maletic, "Videodance - Technology - Attitude shift," 3.

${ }^{7}$ Ibid. 
${ }^{8}$ Sadler's Wells, "BalletBoyz Deluxe Programme."

${ }^{9}$ Cover, "Audience inter/active," 151.

${ }^{10}$ Reason, "Documentation, Disappearance and the Representation of Live Performance," 9.

${ }^{11}$ Warmelick, Harteveld, and Mayer, "Press Enter or Escape to Play," 2.

${ }^{12}$ Willis, "Choose Your Own Adventure," 52-53.

${ }^{13}$ Hershman, "The Fantasy Beyond Control," 267-273.

${ }^{14}$ Ibid. 267.

${ }^{15}$ Ibid. 269.

${ }^{16} \mathrm{lbid} .272$.

${ }^{17}$ Cover, "Audience inter/active," 142-143.

${ }^{18}$ Ibid.

${ }^{19}$ Multimedia traversable software allows users to construct interactive videos by building a "video tree." This "tree" is then not visible to audience members viewing the work, and instead they are able to "traverse" it as an interactive video, following just one branch of the tree at a time.

${ }^{20}$ Perron, "Genre Profile," 128.

${ }^{21}$ Squire, "Cultural Framing of Computer/Video Games," 4.

${ }^{22}$ Gilan and Bingham, "Annotations Updates."

${ }^{23}$ Chad, Matt \& Rob, "Interactive Adventures."

${ }^{24}$ Salem, "Keep fans engaged with Cards \& Ends Screens."

${ }^{25}$ Block, "Eko."

26 'Transmedia' refers to a body of work that connects a story or narrative across multiple media platforms. In the case of The Pan's People Papers, this work incorporated videos uploaded to YouTube and posts on Twitter (and now as an online archive).

${ }^{27}$ Anderson and Zanotti, "Glossary: Pan's People Papers."

${ }^{28}$ Anderson and Zanotti, "A Legion of Echoes."

${ }^{29}$ Johnson, "Intimacy and Risk in Live Art," 122. 
${ }^{30}$ Auslander, Liveness, 13.

${ }^{31}$ Rosenberg, 1.

${ }^{32}$ Gansing, "The Myth of Interactivity or the Interactive Myth?"

${ }^{33}$ O'Connor, "Black Mirror: Bandersnatch."

${ }^{34}$ Rezk and Haahr, "The Case for Invisibility," 183.

${ }^{35} \mathrm{O}^{\prime}$ Connor.

${ }^{36}$ Chaney, "Kimmy Schmidt vs. the Reverend."

${ }^{37}$ Ibid.

${ }^{38}$ Krapp, "Noise Channels," xiv.

${ }^{39}$ Ibid. xviii.

${ }^{40}$ Alleyne Dance, "(Re)United."

\section{References}

"A Legion of Echos." Pan's People Papers. Chor. Lea Anderson, Dir. Marisa Zanotti. 2015. Accessed 23 May 2021. YouTube. https://www.youtube.com/watch?v=E2uTZYwO8M0

Anderson, Lea and Marisa Zanotti. "Glossary." Pan's People Papers. Accessed 23 Aug. 2020. http://panspeoplepapers.com/glossary/

Auslander, Philip. Liveness: Performance in a Mediated Culture. United Kingdom: Routledge, 2008. https://doi.org/10.4324/9780203938133

Black Mirror: Bandersnatch. Dir. David Slade. Ed. Tony Kearns. 2018. Netflix.

Block, Yuni. “Eko.” Accessed 13 July 2020. https://eko.com

Chad, Matt and Rob. "Interactive Adventures" Accessed 29 Aug. 2020. https://www.youtube.com/playlist?list=PL359371BCEB574A6B

Chaney, Jen. "Kimmy Schmidt vs. the Reverend Is What Interactive TV Was Made For." Accessed 10 Aug. 2020 https://www.vulture.com/2020/05/unbreakable-kimmyschmidt-kimmy-vs-the-reverend-netflix-review.html

Cover, Rob. "Audience Inter/active: Interactive Media, Narrative Control and Reconceiving Audience History." New Media \& Society 8.1 (February 2006): 139-158. https://doi.org/10.1177/1461444806059922 
“Deluxe." Prod. Michael Nunn and William Trevitt. 2020. Facebook.

Gansing, Kristoffer. "The Myth of Interactivity or the Interactive Myth?: Interactive Film as an Imaginary Genre." MelbourneDAC: Melbourne DAC 2003 streamingworlds: 5th International Digital Arts \& Culture Conference RMIT University, School of Applied Communication (2003): 39-45. http://citeseerx.ist.psu.edu/viewdoc/ download?doi=10.1.1.577.6981\&rep=rep1\&type $=$ pdf

Gilian, Itamar and Bingham, Aaron. "Annotations Updates - Now It's Easier to Get Interactive" Accessed 20 Aug. 2020. https://blog.youtube/news-andevents/annotations-updates-now-its-easier-to/

Hershman, Lynn. "The Fantasy Beyond Control." Illuminating Video: An Essential Guide to Video Art. Ed. D. Hall and S. J. Fifer. United States of America: Aperture, 1990. 267-273.

"The Intro." Chor. Sarah Golding. 2020 YouTube.

Johnson, Dominic. "Intimacy and Risk in Live Art." Histories and Practices of Live Art. Ed. D. Heddon and J. Klein. China: Palgrave Macmillan, 2012. 121-147. https://doi.org/10.1007/978-1-137-27231-7_6

Krapp, Peter. Noise Channels; Glitch and Error in Digital Culture. Minneapolis: University of Minnesota Press, 2011. https://doi.org/10.5749/minnesota/9780816676248.001.0001

Maletic, Vera. "Videodance: Technology: Attitude Shift." Dance Research Journal 19.2 (1987): 3-7. Accessed 29 Dec. 2020. https://doi.org/10.2307/1478165

O'Conner, Roisin. "Black Mirror: Bandersnatch - How to watch the different endings and what happens." Accessed 07 Feb. 2021. https://www.independent.co.uk/artsentertainment/tv/news/black-mirror-bandersnatch-endings-how-watch-all-five-whathappens-netflix-a8703326.html

Perron, Bernard. "Genre Profile: Interactive Movies." The Video Game Explosion: A History from PONG to Playstation and Beyond. Ed. M. J. P. Wolf. Westport: Greenwood Press, 2008. 128-133.

Reason, Matthew. Documentation, Disappearance and the Representation of Live Performance. United Kingdom: Palgrave Macmillan, 2006. https://doi.org/10.1057/9780230598560

"(Re)United." Alleyene Dance. 2021. Accessed 15 March 2021. https://www.alleynedance.com/reunited/

Rezk, Anna Marie and Haahr, Mads. "The Case for Invisibility: Understanding and Improving Agency in Black Mirror's Bandersnatch and Other Interactive Digital Narrative Works" Conference: International Conference for Interactive Digital Storytelling (ICIDS) At: Bournemouth UK (2020): 178-189. Accessed 11 Feb. 2021. https://doi.org/10.1007/9783-030-62516-0_16 
Rosenberg, Douglas. Screendance: Inscribing the Ephemeral Image. New York: Oxford University Press, 2012. https://doi.org/10.1093/acprof:oso/9780199772612.001.0001

Sadler's Wells. "BalletBoyz Deluxe Programme." Accessed 29 Aug. 2020. https://sadlerswells-downloads.s3-eu-west-

1.amazonaws.com/shows/BalletBoyz_Programme.pdf

Salem, Muli. "Keep fans engaged with Cards \& Ends Screens as we say goodbye to Annotations Editor." Accessed 20 Aug. 2020. https://blog.youtube/news-andevents/keep-fans-engaged-with-cards-end

Squire, Kurt. "Cultural Framing of Computer/Video Games." The International Journal of Computer Game Research. 2.1 (July 2002): http://www.gamestudies.org/0102/squire/

Unbreakable Kimmy Schmidt: Kimmy vs. the Reverend. Prod. Tina Fey, Robert Carlock, Jeff Richmons, Jack Burditt, David Miner, Sam Means, Jerry Kupfer, Dara Schnapper. Ed. Ken Pluto. 2020. Netflix.

Warmelink, Harald., Harteveld, Casper. and Mayer, Igor. "Press Enter or Escape to Play: Deconstructing Escapism in Multiplayer Gaming." DiGRA '09 - Proceedings on the 2009 DiGRA International Conference: Breaking New Ground: Innovation in Games, Play, Practice and Theory (2009): http://www.digra.org/digital-library/publications/press-enter-orescape-to-play-deconstructing-escapism-in-multiplayer-gaming/

Willis, Marissa D. "Choose Your Own Adventure: Examining the Fictional Content of Video Games as Interactive Fictions." The Journal of Aesthetics and Art Criticism 77.1 (Winter 2019): 43-53. https://doi.org/10.1111/jaac.12605 